\title{
IMAGING OF PSORIATIC ARTHRITIS
}

\author{
I. OLIVIERI ${ }^{1}$, E. SCARANO ${ }^{2}$, A. PADULA ${ }^{1}$, S. D'ANGELO ${ }^{1}$ \\ ${ }^{1}$ Rheumatology Department of Lucania, San Carlo Hospital of Potenza and Madonna delle Grazie Hospital of Matera, \\ Potenza and Matera; ${ }^{2}$ Radiology Department, San Carlo Hospital, Potenza, Italy
}

\begin{abstract}
SUMMARY
Imaging of psoriatic arthritis (PSA) is important for two reasons: the differential diagnosis from other arthritides and the assessment of structural damage that can be inhibited by the new drugs such as the anti-TNF $\alpha$ agents.

Plain film radiographic findings of peripheral arthritis have been important in elaborating the concept of PsA as a separate disease entity. Characteristic aspects of psoriatic peripheral arthritis help the differentiation from rheumatoid arthritis. High-resolution ultrasonography (US), US combined with power Doppler (PDUS) and magnetic resonance imaging (MRI) can be used to image joint synovitis of PsA.

Radiologic features of spondylitis associated with psoriasis are similar to spondylitis associated with reactive arthritis and differ from those of primary ankylosing spondylitis (AS) and the spondylitis associated with inflammatory bowel disease. MRI is very sensitive for the early diagnosis of sacroiliitis. There have been no MRI studies on the spine of patients with PSA. In primary AS bone oedema in the vertebral bodies is an indicator of active disease and can ameliorate during anti-TNF $\alpha$ therapy.

Historically, plain film radiography have played a pivotal role in defining enthesitis lesions of SpA. However, entheseal bone changes appear late. US and MRI have proved to be a highly sensitive and non invasive tools.

Recent US and MRI studies on both finger and toe dactylitis have established that dactylitis is due to flexor tenosynovitis and marked adjacent soft tissue swelling with a variable degree of small joint synovitis. There is no evidence of enthesitis of the insertion of the flexor digitorum tendons and of the attachment of the caspsule of the digit joints.
\end{abstract}

Key words: Enthesitis, dactylitis, spondyloarthritis, ultrasound, magnetic resonance, imaging

\section{PERIPHERAL ARTHRITIS}

Plain film radiographic findings have been important in elaborating the concept of psoriatic arthritis (PsA) as a separate disease entity (1).

Characteristic aspects of PsA which help differentiation from rheumatoid arthritis include: predilection for the interphalangeal joints of the fingers and toes; asymmetric joint involvement in hands and feet; marginal erosion with adjacent bone proliferation resulting in "whiskering"; a tendency to ankylosis of the joint; a relative lack of osteoporosis in comparison to the degree of joint involvement; resorption of the tufts of terminal phalangeal of hands and feet (acro-osteolysis); osteolysis of phalangeal, metacarpal and metatarsal bone resulting in tele-

\footnotetext{
Corresponding author:

Ignazio Olivieri

Dipartimento di Reumatologia della Regione Basilicata

Ospedale San Carlo

Contrada Macchia Romana

85100 Potenza, Italy

E-mail: ignazioolivieri@tiscalinet.it
}

scoping digits (arthritis mutilans); periarticular and shaft periostitis; pencil-in-cup deformity (expansion of the base of the distal phalanx combined with "whittling" of the middle phalanx) (2). Four scoring methods for the assessment of structural damage in peripheral joints in PsA, particularly in the context of clinical trials, have been proposed (3). High-resolution ultrasonography (US) and US combined with power Doppler (PDUS) have been validated as sensitive techniques in the disclosure of synovitis in established PsA (4). Studies to establish their role in early PsA are under way (5).

Magnetic resonance imaging (MRI) can measure synovitis of PsA. However, it appears indistinguishable from that of rheumatoid arthritis (6). Some authors have observed inflammation extending far beyond the joint capsule, involving the adjacent soft structures (7).

McGonagle and his colleagues described in great detail the entheseal features that may be seen in association with synovitis in PsA (8). MRI of synovitis of PsA can show bone oedema (9). In rheumatoid arthritis bone oedema is a strong pre- 
dictor of bone erosion (10), but this has not been demonstrated in PsA.

\section{SPINAL DISEASE}

Radiologic features of spondylitis associated with psoriasis are similar to spondylitis associated with reactive arthritis and differ from those of primary ankylosing spondylitis (AS) and the spondylitis associated with inflammatory bowel disease (11). Distinguishing findings include: unilateral or markedly asymmetric involvement of the sacroiliac joint more frequent than in primary AS; nonmarginal, asymmetric, coarse and broad syndesmophytes; severe cervical spine involvement with relative sparing of the thoracolumbar spine; rarity of the typical "bamboo" spine of primary AS.

MRI is very sensitive for the early diagnosis of sacroiliitis. Williamson and his co-workers found MRI evidence of sacroiliitis in $38 \%$ of a group of consecutive and unselected patients with PsA. Sacroiliitis was not indispensably associated with a clinical history of inflammatory low back or buttock pain or positive provocation test (12). The MRI changes detected were similar to those found in patients with primary AS (13) and included bone oedema, erosions, chronic changes of periarticular fat accumulation and sclerosis. There have been no MRI studies on the spine of patients with PsA. In primary AS bone oedema in the vertebral bodies is an indicator of active disease and can ameliorate during anti-TNF $\alpha$ therapy (14).

\section{PERIPHERAL ENTHESITIS}

Inflammation at the entheses, the sites of attachment of tendon, ligament, fascia or joint capsule to bone, is a distinguishing pathological feature of the spondyloarthropathies (SpA) including PsA (15). Oriente et al have found peripheral enthesitis in $20 \%$ of their patiens with psoriatic arthritis (PsA) with a peak value of $30 \%$ in the spondylitic pattern (16). There is also a subset of psoriatic arthritis with isolated enthesitis and/or dactylitis (17).

Historically, plain film radiography have played a pivotal role in defining enthesitis lesions of SpA. These include bone insertion osteopenia, bone cortex irregularity at insertion, erosion, entheseal soft tissue calcification and new bone formation. However, entheseal bone changes appear late and are al- so common in mechanical disorders and in crystal related pathology.

Over the last few years, US has proved to be a highly sensitive and non invasive tool, especially in assessing tendon and joint involvement. Lehtinen et al (18) and Balint et al (19) were the first to describe extensively US B mode aspects of lower limb enthesitis of SpA, revealing the high frequency of asymptomatic US abnormal findings. In B mode, the appearence of enthesitis is characterized by the loss of normal fibrillar echogenicity, by an increasing thickness or intralesional focal changes of tendon insertion, calcific deposits at insertion of the tendon, periosteal changes (erosions or new bone formation). More recently, power Doppler technology has allowed to visualize abnormal vascularization and hyperemia in enthesitis (20).

The first MRI studies in SpA emphasized the extrasynovial nature of inflammatory lesions in synovial joints in SpA but did not identify enthesitis in the same joints (7). The use of Fat Sat MRI has demonstrated that the extracapsular inflammatory lesion in synovial joints of SpA is commonly an enthesitis, and that the inflammatory process associated with enthesitis may be quite extensive, involving the soft tissues and the bone marrow $(7,21$ 23). MRI pattern of SpA enthesitis is characterized by a diffuse bone edema adjacent to enthesis, associated with surrounding soft tissue edema, and increasing ligament and bursa signal intensity after intravenous injection of gadolinium contrast $(22,23)$.

\section{DACTYLITIS}

Dactylitis is one of the clinical manifestations of the SpA. Although more frequent in PsA (24), dactylitis may be observed in all forms of SpA (25). Like other SpA manifestations that is to say, peripheral enthesitis, peripheral arthritis, inflammatory spinal pain, buttock pain, chest wall pain, acute anterior uveitis and aortic regurgitation together with conduction disturbances, dactylitis may sometimes occur for a long time in isolation as the only clinically apparent manifestation of the HLAB27-associated disease process (26).

In the past, it was thought that the sausage-like appearance was due to concomitant flexor tenosynovitis and arthritis of the metacarpophalangeal (or metatarsophalangeal) and interphalangeal joints. Recent US and MRI studies on both finger and toe dactylitis have established that dactylitis is due to 
flexor tenosynovitis and marked adjacent soft tissue swelling with a variable degree of small joint synovitis (27-31). Flexor tenosynovitis was always present while joint synovitis occurred in $17-62 \%$ of the sausage shaped digits. Another important conclusion was that clinical examination was a sufficient method for the diagnosis of tenosynovitis since it showed $100 \%$ sensitivity and specificity compared with MRI $(27,28)$.

Recently McGonagle and his colleagues hypothesized that enthesitis is the primary lesion in SpA and that synovitis of the various structures (joint, tendon and bursa) represents a secondary phenomenon due to the release of pro-inflammatory cytokines from the inflamed entheses $(32,33)$. In their opinion, the flexor tenosynovitis of dactylitis is due to enthesitis as a consequence of the diffusion of cytokines along the tenosynovial sheaths (33). A recent study has demonstrated, by using fast spin echo (FSE)-T2-weighted sequences with fat saturation, that in SpA dactylitis there is no evidence of enthesitis of the insertion of the flexor digitorum tendons and of the attachment of the caspsule of the digit joints (29). However, Mc Gonagle and his colleagues have suggested that in dactylitis enthesitis could occur at the numerous "functional entheses" that the digit flexor tendons forms with retinacula or pulleys (34). These "functional entheses" are frequently associated with the presence of fibrocartilage that reduce compression and shear. This hypothesis could be tested by using high resolution imaging.

\section{REFERENCES}

1. Wright V. Psoriatic arthritis - a comparative study of rheumatoid arthritis and arthritis associated with psoriasis. Ann Rheum Dis 1961; 20: 123-32.

2. Resnick D, Niwayama G. Psoriatic arthritis. In Resnick D, Niwayama, eds. Diagnosis of bone and joint disorders. Philadelphia: WB Saunders. 1981; 1103-29.

3. Van der Heijde D, Sharp J, Wassenberg S, Gladman DD. Psoriatic arthritis imaging: a review of scoring methods 2005; 64 (Suppl II): 61-4.

4. Fiocco U, Cozzi F, Rubaltelli L, et al. Long-term sonographic follow-up of rheumatoid and psoriatic proliferative knee joint synovitis. Br J Rheumatol 1996; 35 : 155-63.

5. Kane D, Pathare S. Early psoriatic arthritis. Rheum Dis Clin N Am 2005; 31: 641-57.

6. Cimmino MA, Parodi M, Innocenti S, et al. Dynamic magnetic resonance of the wrist in psoriatic arthritis reveals imaging patterns similar to those of rheumatoid arthritis. Arthritis Res Ther 2004; 7: R725-31.
7. Jevtic V, Watt I, Rozman B, et al. Distinctive radiological features of small hand joints in rheumatoid arthritis and seronegative spondyloarthritis demonstrated by contrast-enhanced (Gd-DTPA) magnetic resonance imaging. Skeletal Radiol 1995; 24: 351-5.

8. McGonagle D, Conaghan PG, Emery P. Psoriatic arthritis. A unified concept twenty years on. Arthritis Rheum 1999; 42: 1080-6.

9. Savnik A, Malmskov H, Thomsen HS, et al. Magnetic resonance imaging of the wrist and finger joints in patients with inflammatory joint disease. J Rheumatol 2001; 28: 2193-2000.

10. McQueen FM, Benton N, Perry D, et al. Bone oedema scored on magnetic resonance scans of the dominant carpus at presentation predicts radiographic joint damage at the hands and feet six years later in patients with rheumatoid arthritis. Arthritis Rheuum 2003; 48: 181427.

11. McEwen C, DiTata D, Lingg C, et al. Ankylosing spondylitis and spondylitis accompanying ulcerative colitis, regional enteritis, psoriasis and Reiter's disease. Arthritis Rheum 1971; 14: 291-318.

12. Williamson L, Dockerty JL, Dalbeth N, et al. Clinical assessment of sacroiliitis and HLA-B27 are poor predictors of sacroiliitis diagnosed by MRI in psoriatic arthritis. Rheumatol 2004; 43: 85-8.

13. Bollow M, Braun J, Hamm B, et al. Early sacroiliitis in patients with spondyloarthropathy: evaluation with dynamic gadolinium-enhanced MR imaging. Radiology 1995; 194: 529-36.

14. Braun J, Baraliakos X, Golder W, et al. Magnetic resonance imaging examinations of the spine in patients with ankylosing spondylitis, before and after successful therapy with infliximab. Arthritis Rheum 2003; 48: 1126-36.

15. D’Agostino MA, Olivieri I. Enthesitis. Best Pract Res Clin Rheumatol 2006; 20: 473-86.

16. Oriente P, Biondi-Oriente C, Scarpa R. Psoriatic arthritis: clinical manifestations. Baillieres Clin Rheumatol 1994; 8: 277-94.

17. Salvarani C, Cantini F, Olivieri I, et al. Isolated peripheral enthesitis and/or dactylitis: a subset of psoriatiuc arthritis. J Rheumatol 1997; 24: 1106-10.

18. Lehtinen A, Taavitsainen M, Leirisalo-Repo M. Sonographic analysis of enthesopathy in the lower extremities of patients with spondylarthropathy. Clin Exp Rheumatol 1994; 12: 143-8.

19. Balint PV, Kane D, Wilson H, et al. Ultrasonography of entheseal insertions in the lower limb in spondyloarthropathy. Ann Rheum Dis 2002; 61: 905-10.

20. D'Agostino MA, Said-Nahal R, Hacquard-Bouder C et al. Assessment of peripheral enthesitis in the spondyloarthropathies by ultrasonography combined with power Doppler: a cross-sectional study. Arthritis Rheum 2003; 48: 523-33.

21. McGonagle D, Gibbon W, O'Connor P, Green M, Peases C, Emery P: Characteristic MRI entheseal changes of knee synovitis in spondylarthropathy. Arthritis Rheum 1998; 41: 694-700.

22. McGonagle D, Marzo-Ortega H, O’Connor P, Gibbon 
W, Pease C, Reece R, Emery P: The role of biomechanical factors and HLA-B27 in magnetic resonance imaging-determined bone changes in plantar fascia enthesopathy. Arthritis Rheum 2002; 46: 489-93.

23. Marzo-Hortega H, McGonagle D, O'Connor P \& Emery P. Efficacy of etanercept in the treatment of entheseal pathology in resistant spondyloarthropathy: a clinical and magnetic resonance imaging study. Arthritis Rheum 2001; 44: 2112-17.

24. Gladman DD. Psoriatic arthritis. In: Khan MA, ed. Ankylosing Spondylitis and Related Spondyloarthropathies. Spine: State of the Art Review. Philadelphia: Hanley \& Belfus, Inc. 1990: 637-56.

25. Dougados M, van der Linden S, Juhlin R, Huitfeldt B, Amor B, Calin A, et al. The European Spondylarthropathy Study Group preliminary criteria for the classification of spondylarthropathy. Arthritis Rheum 1991; 34: 1218-27.

26. Olivieri I, Scarano E, Padula A, Giasi V, Priolo F. Dactylitis, a term for different digit diseases. Scand J Rheumatol 2006; 35: 333-40.

27. Olivieri I, Barozzi L, Favaro L, Pierro A, De Matteis M, Borghi C, et al. Dactylitis in patients with seronegative spondylarthropathy: assessment by ultrasonography and magnetic resonance imaging. Arthritis Rheum 1996; 39: 1524-8.
28. Olivieri I, Barozzi L, Pierro A, De Matteis M, Padula A, Pavlica P. Toe dactylitis in patients with spondyloarthropathy: assessment by magnetic resonance imaging. J Rheumatol 1997; 24: 926-30.

29. Olivieri I, Salvarani C, Cantini F, Scarano E, Padula A, Niccoli L, et al. Fast Spin Echo-T2-weighted sequences with fat saturation in dactylitis of spondylylarthritis: no evidence of entheseal involvement of the flexor digitorum tendons. Arthritis Rheum 2002; 46: 2964-7.

30. Kane D, Greaney T, Bresnihan B, Gibney R, FitzGerald $\mathrm{O}$. Ultrasonography in the diagnosis and management of psoriatic dactylitis. J Rheumatol 1999; 26: 1746-51.

31. Wakefield RJ, Emery P,Veale D. Ultrasonography and psoriatic arthritis. J Rheumatol 2000; 27: 1564-5.

32. McGonagle D, Gibbon W, Emery P . Classification of inflammatory arthritis by enthesitis. Lancet 1998; 352: 1137-40.

33. McGonagle D, Pease C, Marzo-Ortega H, O’Connor P, Emery P. The case for classification of polymyalgia rheumatica and remitting seronegative symmetrical synovitis with pitting edema as primarily capsular/entheseal based pathologies.J Rheumatol 2000; 27: 837-40.

34. McGonagle D, Marzo-Ortega H, Benjamin M, Emery P. Report on the second international enthesitis workshop. Arthritis Rheum 2003; 48: 896-905. 